А.В.Будневский, В.Т.Бурлачук, А.В.Перцев

Компьютерная система мониторинга хронической обструктивной болезни легких

ГБОУ ВПО "Воронежская государственная медицинская академия им. Н.Н.Бурденко" Минздрава России: 394000, Воронеж, ул. Студенческая, 10

\title{
A.V.Budnevskiy, V.T.Burlachuk, A.V.Pertsev \\ Computed monitoring system for patients with chronic obstructive pulmonary disease
}

\begin{abstract}
Summary
The aim of this study was to improve efficacy of treatment and preventive measures in outpatients with COPD using computed monitoring system. Methods. Clinical course of the disease and outpatient treatment effectiveness in 59 patients with COPD II-III stage (of them, 46 were males) have been analyzed using computed pulmonology register. The age of patients was $59.66 \pm 0.74$ years. Thirty eight patients were vaccinated against influenza infection and 21 patients were not vaccinated.

Results. The computed programme "Monitoring system for patients with chronic obstructive pulmonary disease" demonstrated that vaccination of COPD II to III stage patients reduced rate of acute respiratory infection episodes, hospitalisations, visits to a physician and emergency calls. Conclusion. The computed programme allowed to improve treatment and to analyze efficacy of preventive measures in COPD patients. Vaccination against influenza in COPD patients was highly effective and safe.

Key words: chronic obstructive pulmonary disease, computed register, vaccination.
\end{abstract}

\section{Резюме}

Представлены результаты анализа особенностей клинического течения заболевания и эффективности терапии у больных хронической обструктивной болезнью легких (ХОБЛ) на амбулаторно-поликлиническом уровне с использованием компьютерного пульмонологического регистра. С использованием компьютерной программы "Система мониторинга пациентов с ХОБЛ" показано, что вакцинация больных ХОБЛ ІІ-ІІІ стадии способствует снижению частоты острых респираторных вирусных инфекций, госпитализаций, числа амбулаторных визитов и вызовов скорой медицинской помощи.

Ключевые слова: хроническая обструктивная болезнь легких, компьютерный регистр, вакцинация.

В последние десятилетия одно из наиболее распространенных хронических заболеваний легких - хроническая обструктивная болезнь легких (ХОБЛ) представляет собой важнейшую медико-социальную проблему, отличаясь широкой распространенностью, тенденцией к росту числа случаев тяжелых форм заболевания, инвалидизации и уровня смертности [1, 2].

По утверждению экспертов GOLD (2011), несмотря на неустанные попытки улучшения качества медицинской помощи (МП) больным ХОБЛ, предпринятые за последние 10 лет, большинство из них так и не ощутили на себе прогресса в области терапии заболевания, а многие по-прежнему лишены даже минимальной МП. Задачей будущих лет является работа с врачами и учреждениями первичной МП, а также руководителями здравоохранения в различных странах, направленная на создание, внедрение и оценку программ оказания МП больным ХОБЛ, соответствующих местным потребностям [1, 2]. Оптимальное решение проблемы качества оказания МП возможно только посредством совершенствования организации и управления здравоохранением на основе системного подхода с использованием управленческих алгоритмов.

Актуально создание компьютерной системы мониторинга больных ХОБЛ, с помощью которой воз- можна оптимизация управления лечебно-диагностическим процессом при данном заболевании, повышение клинической эффективности терапии, снижение финансовой нагрузки на здравоохранение и общество в целом.

Целью исследования явилось повышение эффективности лечебно-профилактических мероприятий (вакцинация против гриппа) среди больных ХОБЛ различной степени тяжести на амбулаторно-поликлиническом уровне с использованием компьютерной системы мониторинга пациентов.

\section{Материалы и методы}

В исследование включены больные ХОБЛ ІІ-ІІІ стадии $(n=59 ; 46$ мужчин и 13 женщин; средний возраст - 59,66 0 0,74 года: от 46 до 72 лет). В зависимости от варианта медикаментозной терапии пациенты были распределены на 2 группы: 1-я - больные ХОБЛ II-III стадии $(n=38$; средний возраст $-59,37 \pm$ 1,07 года), которым проводилась вакцинация против гриппа на фоне традиционной терапии основного заболевания. Использовалась противогриппозная вакцина Инфлювак (Solvay Pharma) по общепринятой схеме.

2-ю группу составили больные ХОБЛ II-III стадии $(n=21$; средний возраст $-60,19 \pm 0,79$ года: от 
54 до 65 лет), получавших традиционную терапию при ХОБЛ и отказавшиеся от вакцинации.

Диагноз ХОБЛ был выставлен на основании данных анамнеза, клинической картины заболевания, результатов физикальных, лабораторных и функциональных методов обследования в соответствии с Глобальной стратегией диагностики, лечения и профилактики ХОБЛ (Национальный институт сердца, легких и крови; пересмотр 2006 г.) и Руководством по респираторной медицине (Российское респираторное общество, 2007).

Для анализа эффективности вакцинации с использованием компьютерной программы "Система мониторинга пациентов с ХОБЛ" (свидетельство о государственной регистрации программы для ЭВМ № 2012614120) [4] оценивалась частота: 1) острых респираторных вирусных инфекций (ОРВИ); 2) амбулаторных визитов; 3) вызовов скорой МП (СМП); 4) госпитализаций до вакцинации и через 12 мес. после нее. Учитывалась частота приема антибактериальных средств, связанных с инфекционным (бактериальным) обострением ХОБЛ в указанные сроки.

Для создания компьютерной программы "Система мониторинга пациентов с ХОБЛ" была выбрана мощная, гибкая, масштабируемая среда разработки программного обеспечения Embarcadero Delphi. В качестве системы управления базами данных (СУБД) использовалась хорошо зарекомендовавшая себя персональная СУБД Microsoft Access, в качестве технологии доступа к данным из приложения - ActiveX Data Objects (ADO/dbGo).

Несмотря на то, что программа работает с базами данных (БД), установка дополнительного программного обеспечения не требуется, т. к. операционные системы семейства Windows, начиная с Windows $X P$, уже содержат необходимую для работы с файлами баз данных Microsoft Access библиотеку MDAC. БД состоит из 2 таблиц - Passport (паспортная часть), Medicine (лечебная часть).

Для нормального функционирования программы необходимо выполнение требований к аппаратному обеспечению - процессор не ниже Pentium II 433, $\geq 128$ Мб оперативной памяти, $\geq 8$ Мб для установки программы и дополнительное дисковое пространство для размещения БД. После запуска программы перед пользователем появляется главная форма приложения, содержащая главное меню для вызова всех основных функций программы. Первичной загрузке сведений должна предшествовать процедура подготовки справочников (Области, Районы, Улицы, Лечебно-профилактические учреждения - ЛПУ, Международная классификация болезней - МКБ). Для удобства пользователя для всех справочников предусмотрены интерфейсы (добавление, изменение, удаление записей, импорт, экспорт). После подготовки справочников пользователь может приступать к импорту сведений - для этого в главном меню необходимо выбрать "файл - импорт" или воспользоваться комбинацией $\mathrm{Ctrl}+\mathrm{I}$, при этом необходимо указать расположение *.xls-файла со сведениями.
По имеющимся в БД сведениям, пользователь может формировать отчеты. Предусмотрены 2 отчетные формы. Отчет 1 - "фильтр", простая выборка сведений, отвечающих определенным условиям поиска. Отчет 2 - выборка сведений в разрезе значения определенного значащего признака. В качестве значащего признака могут быть выбраны "Врач", "Группа здоровья", "Группа инвалидности", "ЛПУ", "Льгота", "Пол", "Полнота обследования", "Посещения пульмонолога", "Препараты", "Район", "Состояние учета", "Статус занятости", "Степень тяжести". В зависимости от выбранного признака выбирается его значение. Выходные файлы отчетов имеют формат Microsoft Excel.

Статистическая обработка полученных результатов выполнялась на персональном компьютере с использованием стандартных статистических методов и пакета программ Statgraphics Plus 5.1.

Количественные данные (при нормальном распределении признака) представлены в виде $M \pm m$, где $M$ - выборочное среднее, $m$ - ошибка среднего. Качественные переменные сравнивались с помощью критерия $\chi^{2}$ или точного метода Фишера.

Сравнение количественных показателей проводилось с помощью t-критерия Стьюдента или рангового метода Уилкоксона (для зависимых переменных) и U-теста Манна-Уитни (для независимых групп).

\section{Результаты и обсуждение}

При анализе клинического течения ХОБЛ у пациентов показано, что введение вакцины было безопасно и не приводило к обострению основного заболевания. При введении вакцины были выявлены слабовыраженные местные и умеренные общие поствакцинальные реакции длительностью $\leq 3$ суток.

Через 12 мес. после вакцинации с использованием компьютерной программы "Система мониторинга пациентов с ХОБЛ" оценивались число госпитализаций, частота обострений основного заболевания, ОРВИ, амбулаторных визитов и госпитализаций.

Установлено, что в группе больных, получавших вакцину, через 12 мес. достоверно снизилось число амбулаторных визитов, вызовов СМП, обострений и госпитализаций по поводу ХОБЛ (см. таблицу).

Средняя частота ОРВИ у больных ХОБЛ 1-й группы до вакцинации составила $3,56 \pm 0,16$ случая, в то время как через 12 мес. после вакцинации снизилась в 2,2 раза и составила $1,55 \pm 0,17$ случая $(p<0,05)$.

В течение 1 года до вакцинации 30 (78,9\%) пациентов 1-й группы в связи с инфекционными обострениями ХОБЛ (бактериального характера) были вынуждены принимать антибиотики, в то время как в течение 12 мес. после вакцинации только 15 (39,5 \%) пациентам, страдающим ХОБЛ, потребовалась антибактериальная терапия $\left(\chi^{2}=12,26 ; p=0,0005\right.$; с поправкой Йетса на непрерывность $\left.\chi^{2}=10,68 ; p=0,0011\right)$.

Среднее число курсов антибиотиков по поводу инфекционных обострений ХОБЛ в 1-й группе сни- 
Динамика частоты ОРВИ, амбулаторных визитов, вызовов СМП и госпитализаџий по поводу обострения ХОБЛ в группах сравнения

\begin{tabular}{|c|c|c|c|c|}
\hline \multirow[t]{2}{*}{ Показатель } & \multicolumn{2}{|c|}{ 1-я группа, $n=38$} & \multicolumn{2}{|c|}{ 2-я группа, $n=21$} \\
\hline & Исходно & Через 12 мес. & Исходно & Через 12 мес. \\
\hline ОРВИ & $3,56 \pm 0,16$ & $1,55 \pm 0,17^{\star}$ & $3,67 \pm 0,20$ & $3,90 \pm 0,30$ \\
\hline Госпитализация & $2,57 \pm 0,20$ & $1,02 \pm 0,13^{*}$ & $2,71 \pm 0,30$ & $2,47 \pm 0,21$ \\
\hline Вызов СМП & $4,19 \pm 0,31$ & $2,76 \pm 0,25^{*}$ & $4,23 \pm 0,31$ & $3,81 \pm 0,34$ \\
\hline Амбулаторные визиты & $5,15 \pm 0,40$ & $2,86 \pm 0,21^{*}$ & $5,52 \pm 0,60$ & $4,85 \pm 0,37$ \\
\hline
\end{tabular}

Примечание: * - различия достоверны до и через 12 мес. наблюдения $(p<0,05)$.

зилось в 1,9 раза - с 2,79 $\pm 0,08$ курса на 1 человека до $1,12 \pm 0,07(p<0,05)$.

У больных ХОБЛ 1-й группы достоверно снизилась частота: госпитализаций - с 2,57 \pm 0,20 до 1,02 \pm 0,13 раза в год $(p<0,05)$, вызовы СМП - с 4,19 $\pm 0,31$ до $2,76 \pm 0,25$ раза в год $(p<0,05)$, амбулаторных визитов - с 5,15 $\pm 0,40$ до $2,86 \pm 0,21$ раза в год $(p<0,05)$. Динамика указанных показателей у больных 2-й группы была недостоверной $(p>0,05)$.

Таким образом, применение вакцины у больных ХОБЛ способствовало снижению частоты ОРВИ в 2,2 раза, вызовов СМП - в 1,5 раза, госпитализаций - в 2,1 раза, амбулаторных визитов по поводу ОРВИ или обострения ХОБЛ - в 1,8 раза, госпитализаций - в 2,5 раза.

В настоящее время известно, что среди основных причин прогрессирования ХОБЛ ведущее место занимают повторные тяжелые обострения заболевания. Один из основных факторов, способствующих развитию обострения ХОБЛ, - ОРВИ, в первую очередь - грипп, которым ежегодно страдает огромное число людей во всем мире [5, 6].

Респираторные вирусы являются одним из основных факторов, способных вызывать обструкцию дыхательных путей и усугубить имеющиеся у больных ХОБЛ нарушения бронхиальной проходимости. По данным литературных источников, при сердечно-сосудистой патологии летальность возрастает в 52 раза, а при болезнях легких - в 120 раз (104 и 240 случаев на 100 тыс. населения соответственно). Этот показатель возрастает до 435 случаев у пациентов с гриппозной инфекцией на фоне сочетания сердечно-сосудистой патологии с патологией органов дыхания [3].

При прогрессирующем характере ХОБЛ предполагается неуклонное ослабление естественных защитных систем органов дыхания и создаются благоприятные условия для инфицирования респираторной системы [7]. Инфицирование вирусом гриппа приводит к снижению функциональной активности мерцательного эпителия с последующей атрофией ресничек и параличом цилиарного аппарата. В результате повышается вязкость бронхиального секрета и создаются условия для продвижения инфекционного агента в нижние отделы респираторного тракта [5].

Современная концепция вакцинопрофилактики гриппа ориентирована прежде всего на иммуниза- цию лиц высокого риска заражения, к которым относятся больные ХОБЛ.

Использование компьютерной программы "Система мониторинга пациентов с ХОБЛ" является перспективным методом оценки эффективности вакцинопрофилактики, позволяющим оценивать как фармакоэкономические аспекты терапии больных, так и влияние профилактических мероприятий на клиническое течение заболевания.

\section{Заключение}

Для анализа особенностей клинического течения и эффективности терапии заболевания у больных ХОБЛ рекомендуется использование компьютерной системы мониторинга ХОБЛ, позволяющей оптимизировать тактику медикаментозной терапии и оценивать эффективность профилактических мероприятий при данном заболевании.

В результате исследования клинической эффективности вакцинации больных ХОБЛ показаны высокая фармакоэкономическая эффективность и безопасность применения вакцины Инфлювак: снижются частота ОРВИ, число госпитализаций, вызовов СМП и амбулаторных визитов пациентов, страдающих ХОБЛ II-III стадии.

\section{Литература / References}

1. Будневский А.В., Лукашев В.О., Кожевникова С.А. Рационализация терапии хронической обструктивной болезни легких в амбулаторной практике. Прикладные информационные аспекты медицины. 2011; 14: 15-24. / Budnevskiy A.V., Lukashev V.O., Kozhevnikova S.A. Improvement in outpatient therapy of chronic obstructive pulmonary disease. Prikladnye informatsionnye aspekty meditsiny. 2011; 14: 15-24 (in Russian).

2. Глобальная стратегия диагностики, лечения и профилактики хронической обструктивной болезни легких (пересмотр 2011 г.): Пер. с англ. под ред. А.С.Белевского. M.: PPO; 2012. / Global Strategy of Diagnosis, Treatment and Prevention of Chronic Obstructive Pulmonary Disease (updated 2011). Belevskiy A.S. (editor of Russian version). Moscow, Russian Respiratory Society; 2012 (in Russian).

3. Дидковский Н.А., Малашенкова И.К., Танасова А.Н. ОРВИ и грипп: вопросы профилактики и лечения. Русский медицинский журнал. 2006; 14 (22): 1583-1587. / Didkovskiy N.A., Malashenkova I.K., Tanasova A.N. ARVI and influenza: prevention and treatment. Russkiy meditsinsky zhurnal. 2006; 14 (22): 1583-1587 (in Russian). 
4. Пронин С.С., Будневский А.В., Бурлачук В.Т., Трибунцева Л.В. Мониторинг пациентов с хронической обструктивной болезнью легких: Свидетельство о государственной регистрации программы для ЭВМ № 2012614120; зарегистрировано в Реестре программ для ЭВМ 04.05.2012. / Pronin S.S., Budnevskiy A.V., Burlachuk V.T., Tribuntseva L.V. Monitoring of Patients with Chronic Obstructive Pulmonary Disease: State Registration Certificate of Software N 2012614120; Registered in the Software Register on the $4^{\text {th }}$ of May, 2012 (in Russian).

5. Семенов Б.Ф. Концепция отложенной смерти при гриппе и тактика вакцинопрофилактики инфарктов, инсультов и летальных исходов при этой инфекции. Русский медицинский журнал. 2003; 11 (22): 1266-1267. / Semenov B.F. A conception of delayed death and a strategy of prevention of myocardial infarction, stroke and death in influenza using vaccination. Russkiy meditsinsky zhurnal. 2003; 11 (22): 1266-1267 (in Russian).

6. Синопальников А.И., Романовских А.Г. Инфекционное обострение хронической обструктивной болезни легких. Consilium Medicum. Справочник поликлинического врача. 2007; 11: 54-58. http://consilium-medicum.com/ magazines/cm/pylmo/article/9555 / Sinopal'nikov A.I., Romanovskikh A.G. Infection-related exacerbation of chronic obstructive pulmonary disease. Consilium Medicum. A handbook of a general practitioner. 2007; 11: 54-58. http://consilium-medicum.com/magazines/cm/pylmo/article/9555 (in Russian).

7. Шмелев Е.И. Бактериальная иммунокоррекция при хроническом бронхите и хронической обструктивной болезни легких. Атмосфера. Пульмонология и аллергология. 2005; 1: 35-38. / Shmelev E.I. Bacterial immune correction in patients with chronic bronchitis and chronic obstructive pulmonary disease. Atmosfera. Pulmonologia i allergologia. 2005; 1: 35-38 (in Russian).

\section{Информация об авторах}

Будневский Андрей Валериевич - Д. м. н., профессор, декан факультета подготовки кадров высшей квалификации, зав. кафедрой факультетской терапии ГБОУ ВПО ВГМА им. Н.Н.Бурденко Минздрава России; тел.: (4732) 59-89-90; e-mail: budnev@list.ru

Бурлачук Виктор Тимофеевич - д. М. Н., профессор, проректор по лечебной работе ГБОУ ВПО ВГМА им. Н.Н.Бурденко Минздрава России, зав. кафедрой общей врачебной практики (семейной медицины) ИДПО; тел.: (4732) 52-03-80; e-mail: luvsma@mail.ru

Перцев Александр Владимирович - очный аспирант кафедры факультетской терапии ГБОУ ВПО ВГМА им. Н.Н.Бурденко Минздрава России; тел.: (4732) 63-81-30; e-mail: pertsev.vrn@yandex.ru

Поступила 18.12.13 (с) Коллектив авторов, 2014 удк 616.24-036.12-07:681.3 